\title{
A Rare Cause of Respiratory Distress Syndrome in Full- term Newborn: Obstructive Infracardiac Type Total Anomalous Pulmonary Venous Connection
}

\author{
Sabriye Korkut ${ }^{*}$, Mustafa Argun ${ }^{2}$, Hulya Halis ${ }^{1}$, Ahmet Ozdemir ${ }^{1}$, Osman Bastug ${ }^{1}$, Levent Korkmaz ${ }^{1}$ and Tamer \\ Gunes $^{1}$
}

${ }^{1}$ Division of Neonatalogy, Department of Pediatrics, Erciyes University, Turkey

${ }^{2}$ Division of Pediatric Cardiology, Department of Pediatrics, Erciyes University, Turkey

Received: 跙 Ocotber 01, 2018; Published: 制 October 08, 2018

*Corresponding author: Sabriye Korkut, Division of Neonatalogy, Department of Pediatrics, Erciyes University, Faculty of Medicine, Talas Street, Kayseri, Turkey

\begin{abstract}
Total anomalous pulmonary venous connection (TAPVC) may cause clinical signs and symptoms of resistant to treatment respiratory distress syndrome (RDS) in the full-term newborn. Despite echocardiography being the basic diagnostic examination method, three-dimensional reconstructive computed tomography allows making a more precise operation plan by defining the anatomy in an excellent manner. Cardiologic evaluation should be done immediately in the case of RDS with treatment-resistant full-term newborn because a delay in the diagnosis increases operative mortality.
\end{abstract}

Keywords: Term Newborn; Respiratory Distress Syndrome; Total Anomalous Pulmonary Venous Connection; Tomography

\section{Introduction}

Respiratory distress syndrome (RDS) is one of the main problems with premature infants and it develops as a result of surfactant deficiency due to lung immaturity. RDS is much rare in full-term newborns, and it usually appears in some clinical conditions causing secondary surfactant deficiency [1,2]. Particularly the obstructive type of total anomalous pulmonary venous connection (TAPVC), in which pulmonary veins drain into systemic venous structures or directly into right atrium without having any direct connection to left atrium, cause RDS by leading to severe pulmonary congestion. In this report it is reemphasized that obstructive TAPVC should be searched for an etiology of treatment resistant respiratory distress in the full-term newborn.

\section{Case Report}

A newborn delivered by cesarean section at 38 weeks with a birth weight of 3100 grams and an apgar score of 5 at 1 minute and 6 at 5 minutes had been admitted to the newborn intensive care unit of an outside center for post-delivery respiratory distress. Upon increasingly worsening respiratory distress under mechanic ventilation and antibiotic therapy, the patient was referred to our clinic with the diagnosis of treatment resistant respiratory distress syndrome on the 7th day of life. There was no history of maternal drug usage, premature rupture of membranes, meconium aspiration, and perinatal asphyxia. There was no history of parental consanguinity and there were no similar cases in the pedigree. On physical examination, the newborn had a body weight of 3300 grams ( $50^{\text {th }}-75^{\text {th }}$ percentile), height of $50 \mathrm{~cm}$ (50th percentile), head circumference of $36 \mathrm{~cm}$ (75th percentile), heart rate of $140 \mathrm{bpm}$, respiratory rate of 72 breaths/minute, arterial blood pressure of $44 / 25 \mathrm{mmHg}$ (mean $35 \mathrm{mmHg}$ ), and oxygen saturation of $90 \%$ (under mechanical ventilation support). The clinical condition was extremely poor; the newborn was dyspneic, had a poor peripheral circulation, and edematous eyelids and lower extremities. No murmur was heard on auscultation but respiratory sounds were diminished and there were bilateral crackles. Liver was palpable $5 \mathrm{~cm}$ below costal margin. Laboratory examinations revealed respiratory and metabolic acidosis, a white blood cell count of $7460 / \mathrm{mm}^{3}$, hemoglobin count of $12.2 \mathrm{~g} / \mathrm{dL}$, thrombocyte count of $251000 / \mathrm{mm}^{3}$, negative C-reactive protein, creatinine of $0.6 \mathrm{mg} / \mathrm{dL}$, alanine aminotransferase of $17 \mathrm{IU} / \mathrm{L}$, aspartate aminotransferase of $67 \mathrm{IL} / \mathrm{L}$, prothrombin time of 12.2 seconds, and activated partial thromboplastin time of 37.6 seconds. Ground glass appearance 
and dilated right atrium was observed on teleradiography (Figure 1). Antibiotic treatment was started due to rule-out pneumonia. High frequency ventilation was applied because of need to high pressure support. Fluid restriction was performed due to oligury, and generalized edema.

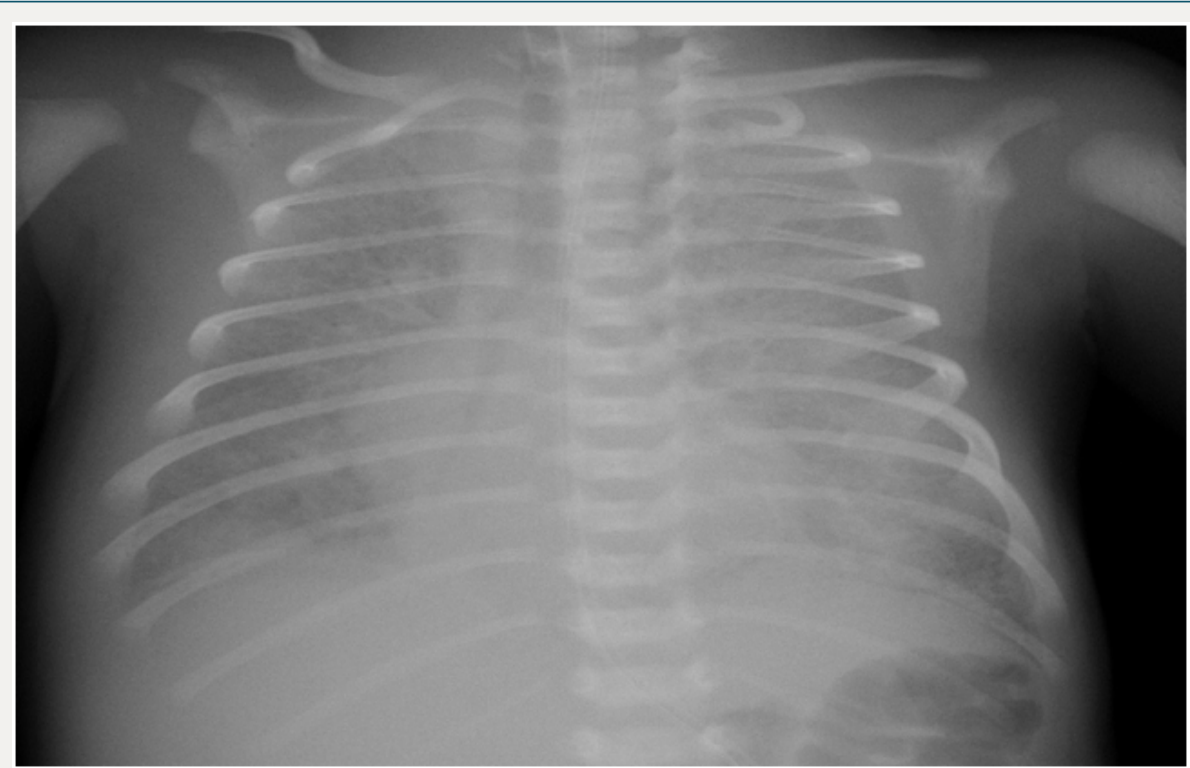

Figure 1: Teleradiography shows ground glass appearance and dilated right atrium.

Blood transfusions were applied because of recurrent pulmonary hemorrhage. Circulation of patient was supported with inotropic agents. No clinical improvement could be achieved in the patient despite the application of high frequency oscillatory ventilation, inotropic agents, magnesium sulfate infusion, and surfactant treatment. An echocardiographic examination revealed dilated right heart chambers, leftward doming of interatrial septum, a right-to-left shunt through a small secundum type atrial septal defect, and patent ductus arteriosus. Pulmonary veins had no relationship with the left atrium. The parasternal long axis view demonstrated an infradiaphragmatic systemic venous connection of an abnormal descending vein (Figure 2). A three-dimensional reconstructive computed tomography delineated the confluence of all pulmonary veins to form the abnormal descending vein which drained into portal vein after an Infracardiac course (Figure 3). The patient was subsequently taken to corrective surgery for TAPVC on the postnatal $10^{\text {th }}$ day; however, the patient died because of low cardiac output syndrome during the surgery.

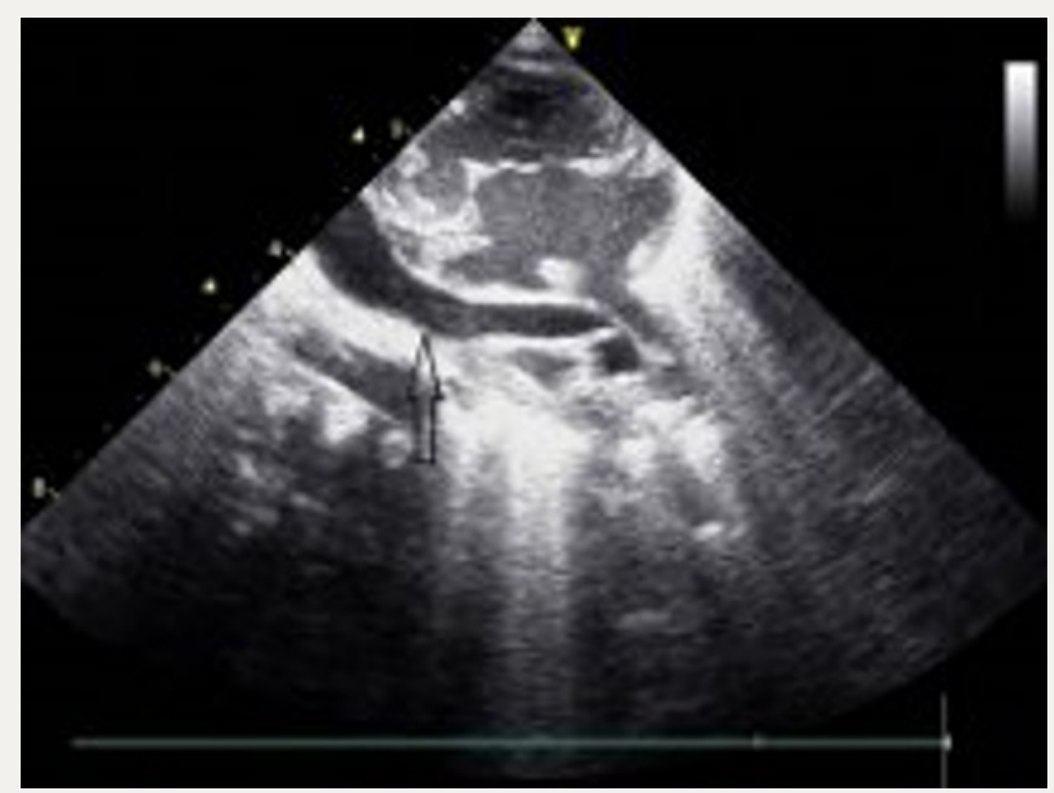

Figure 2: The parasternal long axis echocardiography view demonstrate an infradiaphragmatic systemic venous connection of an abnormal descending vein. 


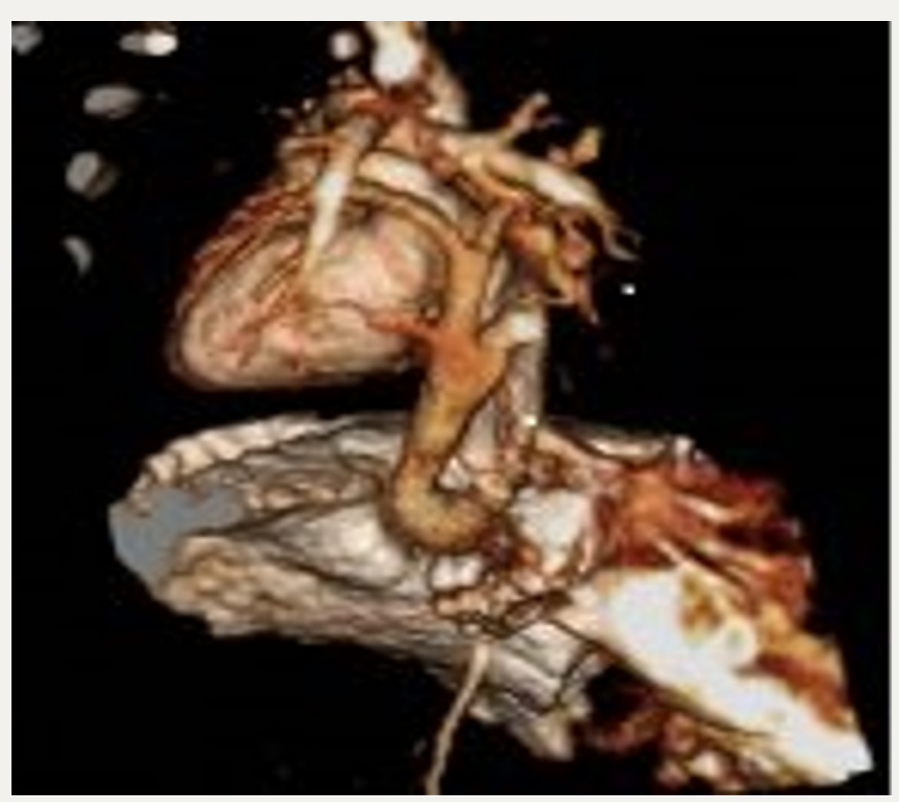

Figure 3: A three-dimensional reconstructive computed tomography delineated the confluence of all pulmonary veins to form the abnormal descending vein which drained into portal vein after an Infracardiac course.

\section{Discussion}

In full-term newborns RDS usually develops as a result of secondary surfactant deficiency due to inflammatory mediators and plasma proteins passing to alveolar space and inactivating surfactant, or reducing surfactant production and release by directly injuring type 2 pneumocytes. Asphyxia, meconium aspiration, pneumonia, sepsis, shock, disseminated intravascular coagulation, pulmonary hemorrhage and pulmonary edema can cause RDS in full-term newborns [1,2]. In the current case, gradual reduction in pulmonary aeration and development of white lung appearance on teleradiogram despite intensive respiratory support suggested a congenital heart disease characterized by a significant left-to-right shunting causing pulmonary congestion and/or pulmonary venous obstruction. TAPVC is a rare congenital heart defect and constitutes 1-3\% of all congenital heart diseases. It has four categories, namely the supracardiac, cardiac, infracardiac, and mixed types. In the infracardiac type the pulmonary confluence most commonly drains into portal vein. It is usually with an obstruction in the pulmonary venous connection. Obstruction of pulmonary blood flow leads to pulmonary venous hypertension and, through reflection to pulmonary capillary bed, pulmonary edema. Clinical presentation depends on the severity of pulmonary venous flow obstruction. Newborns with obstructed TAPVC present with cyanosis and respiratory distress unresponsive to treatment $[3,4]$. Traditionally, TAPVC is evaluated with echocardiography and angiography. However, advances in CT scanning technology in recent years have led to excellent spatial and temporal resolution as well as to a significant reduction in radiation dose. Thanks to its rapid completion, it is particularly useful in newborns that are in critical condition due to TAPVC. Hence, as an excellent noninvasive method for the assessment of pulmonary venous return and systemic venous connection, the use of CT angiography has become widespread [5]. Preoperative clinical and morphological features are important risk factors for postoperative pulmonary venous obstruction and survival. Infants with Infracardiac type TAPVC have a worse preoperative clinical status. It has been speculated that the obstruction of pulmonary veins leads to pulmonary venous remodeling and progressive changes [6]. We think that the overall poor preoperative condition of our case was the main reason of the operative mortality.

\section{Conclusion}

Obstructive TAPVC leading to pulmonary congestion and thereby RDS by causing pulmonary venous hypertension and pulmonary blood flow increase should be kept in mind. An early diagnosis is essential since a delay in diagnosis is the main cause of increased operative mortality. Although TAPVC is primarily diagnosed by echocardiography, three dimensional CT can be used in order to provide a precise information about the anatomy of abnormal pulmonary venous connection before a surgical intervention.

\section{References}

1. Liu J, Shl Y, Dong JY, Zheng T, Li JY, et al. (2010) Clinical characteristics, diagnosis and management of respiratory distress syndrome in fullterm neonates. Chin Med J 123(19): 2640-2644.

2. Bessinger R, Carlson C, Hulsey T, Eicher D (2004) Secondary surfactant deficiency in neonates. J Perinatology 24(10): 663-666.

3. Ahmet Özkara, Gürkan Çetin, Murat Mert, Atıf Akçevin, Tufan Paker, et al. (2005) Total anormal pulmonary venous connection and surgical options: experience with 61 cases. The Turkish Journal of Thoracic Cardiovascular Surgery 13(4): 329-334. 
4. Karamlou T, Gurofsky R, Sukhni EA, Coles JG, Williams WG, et al. (2007) Factors associated with mortality and reoperation in 377 children with total anomalous pulmonary venous connection. Circulation 115: 15911598.

5. Dyer KT, Hlavacek AM, Meinel FG, De Cecco CN, McQuiston AD, et al (2014) Imaging in congenital pulmonary vein anomalies: the role of computed tomography. Pediatr Radiol 44(9): 1158-1168.
6. Seale AN, Uemura H, Webber SA, Partridge J, Roughton M, et al. (2010) Total anomalous pulmonary venous connection: morfology and outcome from an international population-based study. Circulation 122(25): 2718-2726.

\section{(C) \\ This work is licensed under Creative Commons Attribution 4.0 License}

To Submit Your Article Click Here:

Submit Article
DOI: $10.32474 /$ PAPN.2018.01.000122

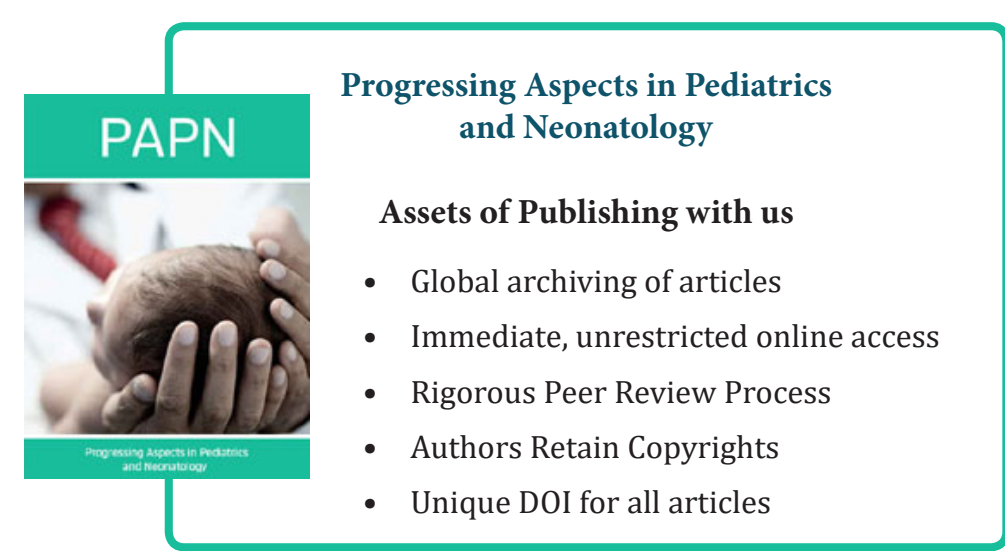

